\title{
Визначення впливу технологічних чинників на процес інтенсифікації пневмоударного штампування витягуванням і точність штампованих деталей
}

\author{
${ }^{1}$ Національний університет «Полтавська політехніка імені Юрія Кондратюка» \\ ${ }^{2}$ Кременчуцький національний університет імені Михайла Остроградського
}

Робота присвячена експериментальним дослідженням 3 визначення впливу технологічних чинників на процес інтенсифікації пневмоударного штампування витягуванням і точність штампованих виробів.

Процес пневмоударного витягування, як і інші імпульсні методи витягування (вибухове, електрогідравлічне та магнітоімпульсне) ускладнюється високою швидкістю деформування i, відповідно, виникненням значних інерційних сил, які протидіють переміщенню фланця деталі, що витягується. При пневмоударному витягуванні зниження швидкості деформування можливо досягти регулюванням відносної маси бойка або застосуванням двохударного витягування. Експериментально підтверджено, що найбільше впливають на граничні показники штампувальної здатності при пневмоударному штампуванні властивості матеріалу заготовки, властивості її поверхні, схема процесу деформування, швидкість деформування, геометрія матриці або пуансона, величина контактного тертя і прийоми інтенсифікації, що застосовуються. Результати експериментів показали, що найбільший вплив на граничний ступінь витягування і якість виробів мають такі фрактори: стан поверхні і фрізико-механічні властивості матеріалу заготовки; радіус заокруглення робочої кромки матриці; відносна товщина заготовки; швидкість навантажування заготовки (параметр $\alpha$ ); фрикційні властивості матеріалу матриці і заготовки; якість змащення; технологічна схема виконання операції. При двохударному витягуванні збільшується граничний ступінь витягування на 8..10\%. Також при використанні двохударного навантаження, як показали експерименти, зменшується величина потоншення в небезпечних перерізах готового виробу. При цьому зменшення радіальних деформацій в центрі зразків сягає $20 . .25 \%$. Точність пневмоударного штампування рідиною дуже висока, оскільки відхилення вимірюваних діаметрів не перевищує 0,1 мм. Якість поверхні відштампованих пневмоударним методом виробів визначається тільки якістю поверхні вихідного матеріалу. Пневмоударний метод штампування з використанням двоступінчастого складеного бойка дозволяє за рахунок двохударного навантаження підвищити ступінь витягування, точність і якість, тобто інтенсифікувати процес глибокого витягування тонколистових виробів. Інтенсифрікація відбувається шляхом послідовного подвійного ударного навантаження за один цикл роботи установки ПУШ. Перший удар $\epsilon$ формоутворювальним, а наступний удар другого ступеня бойка - калібрувальним.

Ключові слова: інтенсифікація, пневмоударне штампування, двохударне витягування, складений бойок.

\section{Вступ}

Процес витягування плоскої заготовки $€$ одним 3 найскладніших в операціях як звичайного, так і імпульсного штампування. Процес пневмоударного витягування, як і інші імпульсні методи витягування (вибухове, електрогідравлічне та магнітоімпульсне) ускладнюється високою швидкістю деформування i, відповідно, виникненням значних інерційних сил, які протидіють переміщенню фланця деталі, що витягується. При пневмоударному витягуванні зниження швидкості деформування можливо досягти регулюванням відносної маси бойка або застосуванням двохударного витягування. 
У процесі витягування кільцева частина заготовки перетворюється в циліндр діаметром $d$ і висотою $h$. Оскільки об'єм металу при витягуванні не змінюється, то при повному витягуванні циліндра висота деталі $h €$ більшою ширини кільцевої частини:

$$
h=b \frac{D+d}{2 d}=b \frac{k+1}{2},
$$

де $k=D / d$ - ступінь витягування; $D$ - діаметр заготовки; $d$ - діаметр деталі.

\section{Основний матеріал}

Керування перебігом процесу фрормоутворення тонколистових деталей, одержання необхідних показників якості, форми, геометрії і точності деталей, що штампуються, збільшення при цьому граничних коефіцієнтів штампувальної здатності матеріалу досягається доступними при проектуванні і реалізації процесу конструктивно-технологічними заходами. Підвищення стійкості також дозволяє знизити процент бракованих деталей (гофри на фрланці і хвилястість на поверхні штампування) (рис. 1), що виникає в процесі деформування.

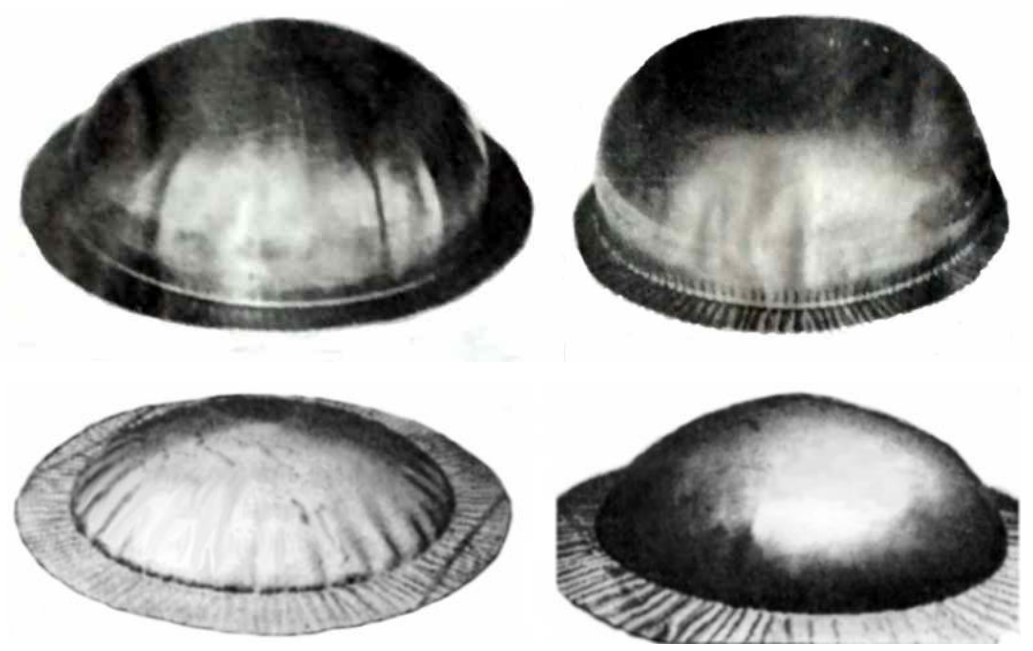

Рис. 1. Характерний брак виробів при високошвидкісному витягуванні тонколистових деталей (хлопуни, гофри на фланці, нерівномірне втягування матеріалу)

Ефективність пневмоударного штампування (ПУШ) рідиною оцінювали за допомогою загальноприйнятих показників штампувальної здатності, що визначають весь технологічний процес за видом деформування заготовки.

Експериментально підтверджено, що найбільше впливають на граничні показники штампувальної здатності при пневмоударному штампуванні властивості матеріалу заготовки, властивості її поверхні, схема процесу деформування, швидкість деформування, геометрія матриці або пуансона, величина контактного тертя і прийоми інтенсифікації, що застосовуються. При переході до іншого виконання обладнання, використовуючи показник (1), можна оцінювати напрямок зміни процесу, а отже, здійснювати керування ним. Відпрацювання методики оцінювання ефективності здійснювали для випадку процесу ПУШ витягуванням.

Результати експериментів показали, що найбільший вплив на граничний 
ступінь витягування і якість виробів мають такі фрактори: стан поверхні і фрізикомеханічні властивості матеріалу заготовки; радіус заокруглення робочої кромки матриці; відносна товщина заготовки; швидкість навантажування заготовки (параметр а); фррикційні властивості матеріалу матриці і заготовки; якість змащення; технологічна схема виконання операції [9, 10].

Перелічені фактори однаково впливають на всі матеріали, що використовуються, а загальний ступінь більш за усе залежить від пластичних властивостей матеріалів.

Однак підвищення пластичних властивостей матеріалів при збільшенні швидкості деформації, з одного боку, і виникнення додаткових динамічних напружень, 3 іншого, впливають на граничний ступінь витягування за зворотними залежностями. Тому його експериментальне визначення в певних умовах пневмоударного навантаження становить безперечний інтерес.

Значення граничного ступеня витягування визначали побудовою графіків штампувальної здатності для двох схем витягування - вільного одноударного та вільного двохударного за допомогою спеціального складеного бойка (рис. 2, б), який має рухомий вкладиш, що дозволяє виконувати подвійний удар за один цикл роботи обладнання. В експериментах використовували циліндричну робочу камеру 2 (рис. 2, а) з внутрішнім діаметром 50 мм. Об'єм води в камері становив $176 \cdot 10^{-6} \mathrm{~m}^{3}$, маса бойка $1-1,471$ кг, що відповідає параметру $\alpha=0,119$. Циліндричні стаканчики витягували в матрицю 7 діаметром $d_{M}=30$ мм. Радіус заокруглення витяжного змінного кільця 6 становив $4 S$.

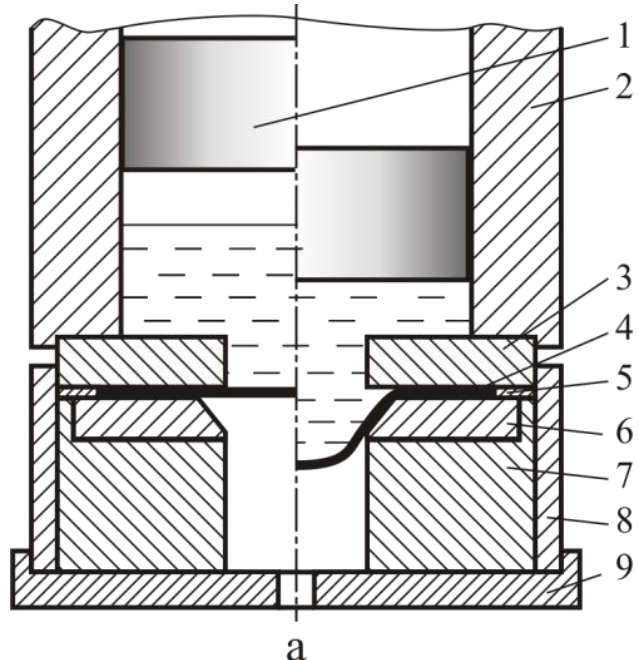

Рис. 2. Експериментальне оснащення для витягування рідиною:

а - вільне; б - вільне зі складеним бойком: 1 - бойок; 2 - робоча камера;

3 - притискач; 4 - заготовка; 5 - центрувальна шайба; 6 - витяжне змінне кільце; 7 - матриця; 8 - обойма; 9 - притискна плита; 10 - рухомий вкладиш

Для проведення експериментів використовували круглі заготовки відносною товщиною $0,014 \leq S / D_{3} \leq 0,02$ з матеріалів АМцМ, Д1АМ, М1М, АМг3М, АМг6М, Л62, ЭИ659, ЭИ878, 12Х8Н10Т, ВЖ98, ЭП693ВД і відносною товщиною $0,006 \leq S / D_{3} \leq 0,012$ з матеріалів 08кп, 08пс, 10кп, ЭИ894, ВТ1-0, ОТ4, ОТ4-1. Заготовки перед витягуванням ретельно змащували. Діаметри заготовок, які витягували, дорівнювали 40, 45, 50, 55, 60, 65, 70 мм. 
При проведені експериментів встановлювали енергію удару, при якій відбувається повне витягування (якщо це можливо) або руйнування заготовки, граничний діаметр заготовки, що витягується під час одноразового навантаження, і відповідне йому значення граничного ступеня витягування $k_{n p 0}$.

Отримані криві штампувальної здатності матеріалу Д1АМ при вільному витягуванні і матеріалу АМцМ при витягуванні зі складеним бойком показані на рис. 3.

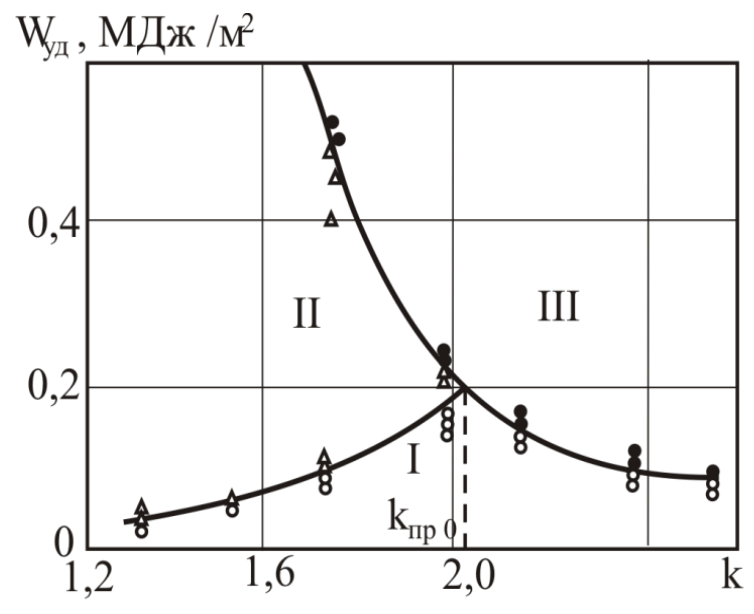

a

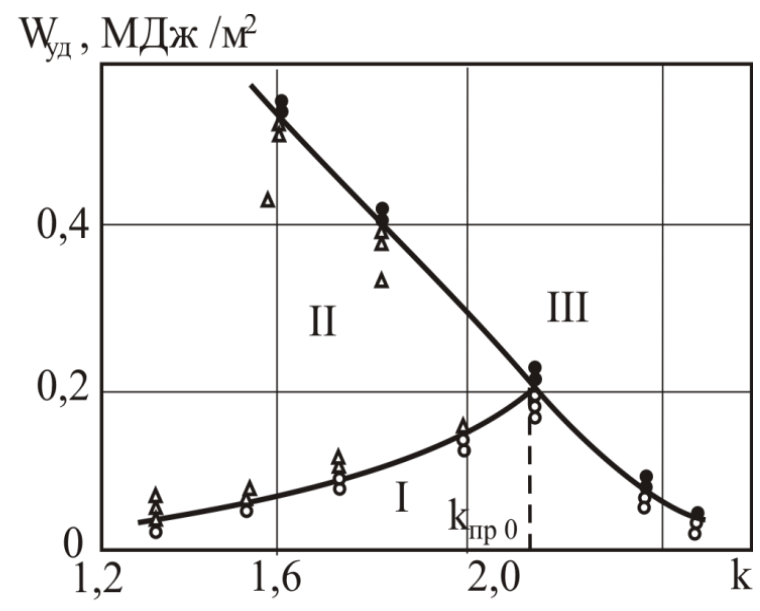

6

Рис. 3. Графріки штампувальної здатності:

а - матеріалу Д1АМ при вільному витягуванні,

б - матеріалу АМцМ при вільному витягуванні зі складеним бойком;

I, II - неповне і повне витягування, III - руйнування заготовки;

॰, $\Delta, \bullet-$ зразки, витягнуті відповідно: частково, повністю і зруйновані

Визначено межі трьох характерних областей. Область I визначається такими співвідношеннями питомої енергії удару бойка $W_{y \partial}$ і початкових ступенів витягування $k$, при яких можна отримати тільки неповне витягування. Область II визначається такими співвідношення цих величин, при яких відбувається повне витягування заготовки, а область III характеризується тим, що при будьякому значенні ступеня витягування заготовка руйнується. Загальна для всіх трьох областей точка на кривих штампувальної здатності відповідає граничному ступеню витягування $k_{n p} 0$. Значенню граничного ступеня витягування відповідає тільки одне певне значення питомої енергії удару бойка, що забезпечує повне витягування заготовки в той час, як будь-якому іншому ступеню витягування (менше граничного) відповідає діапазон значень питомої енергії удару бойка, при якому також забезпечується повне витягування заготовки. Цей діапазон зменшується зі збільшенням ступеня витягування і наближення його до граничного, отже, чутливість матеріалів до надлишкової енергії зростає із збільшенням ступеня витягування.

Як показали результати досліджень, зі збільшенням швидкості деформування ступінь витягування зменшується, отже, здійснення процесу деформування заготовки двома імпульсами дозволить збільшити ступінь витягування, оскільки швидкість деформування в цьому випадку знижується, а тривалість навантаження заготовки збільшується (табл. 1). 
Таблиця 1

Граничний ступінь пневмоударного витягування конструкційних матеріалів

\begin{tabular}{|c|c|c||c|c|c|}
\hline \multirow{2}{*}{ Матеріал } & \multicolumn{2}{|c|}{ Витягування } & \multirow{2}{*}{ Матеріал } & \multicolumn{2}{|c|}{ Витягування } \\
& вільне & двохударне & & вільне & двохударне \\
\hline АМцМ $^{1}$ & 1,94 & 2,13 & Х13 & 1,92 & 2,11 \\
\hline АМг6М & 1,87 & 2,05 & ЭИ878 & 2,1 & 2,31 \\
\hline М1М $^{1}$ & 1,91 & 2,10 & ЭИ402 & 1,97 & 2,13 \\
\hline АМг3М & 1,77 & 1,95 & 12 Х18Н10Т & 2,03 & 2,19 \\
\hline л62 & 1,94 & 2,13 & ЭИ894 & 2,02 & 2,17 \\
\hline Сталі: & & & ЭП693ВД & 1,95 & 2,05 \\
\hline 30ХГСА & 1,45 & 1,6 & ВТ1-0 $^{1}$ & 1,78 & 1,96 \\
\hline 08кп & 1,95 & 2,15 & ОТ4-1 $^{1}$ & 1,6 & 1,76 \\
\hline ЭИ659 & 1,49 & 1,6 & ОТ4 $^{1}$ & 1,54 & 1,69 \\
\hline
\end{tabular}

$\left({ }^{1}\right)$ - дані [8].

Як показали результати експериментальних досліджень, при двохударному витягуванні збільшується граничний ступінь витягування на 8...10\%. Також при використанні двохударного навантаження зменшується величина потоншення в небезпечних перерізах готового виробу. При цьому зменшення радіальних деформацій в центрі зразків сягає $20 \ldots 25 \%$.

Для визначення точності і якості виготовлення поверхні з'єднувальних трубних переходів півсферичної форми вибрано два розміри: внутрішній діаметр в області екватора півсорери $D$ і внутрішній діаметр в області стикування з трубкою $d$. До цих розмірів пред'являються основні вимоги. При інструментальному штампуванні ці діаметри виробів в подальшому піддаються механічному обробленню різанням. У виготовлених півсферах діаметри $D$ і $d$ вимірювали з точністю до 0,01 мм у двох взаємно перпендикулярних напрямах уздовж і впоперек напряму прокатування. Усереднені результати вимірювань наведені в табл. 2. Крім діаметрів $D$ і $d$ тут подані їх максимальні відхилення від номінального значення $\Delta_{D \max }$ і $\Delta_{d \max }$ відповідно, а також товщина вихідного листа $S_{0}$.

Як видно з табл. 2, точність пневмоударного штампування рідиною дуже висока, тому що відхилення вимірюваних діаметрів не перевищує 0,1 мм. Для деталей таких розмірів в довідниках з холодного штампування наводяться допустимі відхилення діаметрів на порядок більше $( \pm 0,4 \ldots 0,9$ мм) від відхилень $(0,05 \ldots 0,1$ мм), що отримані під час пневмоударного штампування. 
Таблиця 2

Розміри виготовлених деталей за допомогою двохударного бойка

\begin{tabular}{|c|c|c|c|c|c|}
\hline Матеріал & $S_{0}$, мм & $D$, мм & $d$, мм & $\Delta_{D \text { max }}$, мм & $\Delta_{d \text { max }}$, мм \\
\hline \multirow{2}{*}{ АМцM } & \multirow{2}{*}{$2,94 \pm 0,15$} & 189,96 & 59,95 & $-0,09$ & $-0,07$ \\
& & 189,99 & 60,0 & $-0,08$ & $-0,05$ \\
\hline \multirow{2}{*}{ М1M } & \multirow{2}{*}{$3,07 \pm 0,13$} & 189,98 & 59,95 & $-0,07$ & $-0,10$ \\
& & 190,01 & 59,96 & $+0,05$ & $-0,08$ \\
\hline \multirow{2}{*}{ 12Х18Н10Т } & \multirow{2}{*}{$2,97 \pm 0,11$} & 189,97 & 59,94 & $-0,10$ & $-0,09$ \\
& & 189,94 & 59,98 & $-0,06$ & $-0,05$ \\
\hline
\end{tabular}

Що стосується якості поверхні відштампованих пневмоударним методом виробів, то вона визначається тільки якістю поверхні вихідного матеріалу. Шорсткість вихідних листових матеріалів вимірювали цифровим профрілометром «Абрис ПМ7М». Середня шорсткість листів $R_{a}$ коливалася від 0,63 до 0,94 мкм, а шорсткість поверхонь отриманих виробів знаходилася в аналогічних межах. Візуальне дослідження інших матеріалів підтверджує висновок, що якість поверхні виробів, отриманих пневмоударним методом штампування 3 використанням двоступінчастого складеного бойка, визначається тільки станом вихідної заготовки.

\section{Висновки}

Проведені дослідження показали, що пневмоударний метод штампування з використанням двоступінчастого складеного бойка дозволяє за рахунок двохударного навантаження підвищити ступінь витягування, точність і якість, тобто інтенсифікувати процес глибокого витягування тонколистових виробів. Інтенсифікація відбувається внаслідок послідовного подвійного ударного навантаження за один цикл роботи установки ПУШ. Перший удар $\epsilon$ формоутворювальним, а наступний удар другого ступеня бойка калібрувальним.

\section{Список літератури}

1. Фролов, Е. А. Показатели качества современных технологических систем импульсного фрормообразования сложнорельефных деталей / Е. А. Фролов // Технологические системы. - 2002. - № 6. - С. 23 - 26.

2. Фролов, Е. А. Пневмоударная и статикодинамическая штамповка сложнорельефных листовых деталей упругими средами: монографрія / Е. А. Фролов [и др.]. - Харьков.: УкрГАЖТ, Краматорск: ДГМА, изд. центр НТУ«ХПИ», - 2010. - 286с.

3. Крыжный, Г. К. Исследование, разработка и внедрение штамповки листовых деталей двигателей летательных аппаратов на гидродинамических пресспушках с интенсификацией процессов мультипликаций давления : дис. ... канд. техн. наук / Григорий Кириллович Крыжный. - Харьков, - 1980. - 187 с.

4. Романовский, В.П.Справочник по холодной штамповке / В. П. Романовский. - 5-е изд., доп. и перераб. - Л. : Машиностроение, 1971. - 782 с. 
5. Бычков, С. А. Концепции применения и реализации импульсных технологий в условиях опытного и серийного производства транспортных самолетов : дис. ... д-ра техн. наук / Сергей Андреевич Бычков. - Харьков, - 1991. - 380 с.

6. Валиев, С. А. Комбинированная глубокая вытяжка листовых материалов / С. А. Валиев. - М.: Машиностроение, - 1973. - 176 с.

7. Норицын, И .А. Теоретический анализ процесса вытяжки листового материала / И.А. Норицын // Изв. АН СССР, ОТН. - 1951. - № 11. - С. 1696 - 1703.

8. Петраковский, В. С. Оценка штампуемости материалов при гидроударной вытяжке листового металла / В. С. Петраковский // Импульсные методы обработки металлов. - Москва: Наука и техника, 1977. - С. 123 - 131.

9. Ясько, С. Г. О степени влияния конструктивно-технологических факторов на процесс пневмоударной вытяжки / С. Г. Ясько // Открытые информационные и компьютерные интегрированные технологии. - 2018. - Вып. 79. - С. 31- 37.

10. Манаенков, И.В. Повышение точности и качества рабочих поверхностей деталей методом пневмоударной штамповки / И. В. Манаенков, Н. К. Резниченко, Е. А. Фролов // Машиностроение: зб. наук. праць. Укр. інж.пед. академії. - Харків: УІПА. - 2012. - № 9. - С. 142 - 147.

\section{References}

1. Frolov, E.A. Pokazateli kachestva sovremennykh tekhnologicheskikh sistem impul'snogo formoobrazovaniya slozhnorel'efnykh detalei [Quality indicators of modern technological systems of pulse shaping of complex relief parts] / E.A. Frolov // Tekhnologicheskie sistemy. - Kyiv, 2002. - № 6. - pp. $23-26$.

2. Frolov, E.A., Movshovich A.Ya. i dr. Pnevmoudarnaya i statikodinamicheskaya shtampovka slozhnorel'efnykh listovykh detalei uprugimi sredami. [Pneumatic impact and static-dynamic stamping of complex relief sheets with elastic media] / E.A. Frolov, A.Ya. Movshovich, I.V. Manaenkov. - Khar'kov: UkrGAZhT, Kramatorsk: DGMA. - 2010. - 287 p.

3. Kryzhnyi,G.K. Issledovanie, razrabotka i vnedrenie shtampovki listovykh detalei dvigatelei letatel'nykh apparatov na gidrodinamicheskikh press-pushkakh $\mathrm{s}$ intensifikatsiei protsessov mul'tiplikatsii davleniya. [Research, development and implementation of stamping of sheet parts of aircraft engines on hydrodynamic press guns with intensification of pressure animation processes]: dis. ... kand. tekhn. nauk / Grigorii Kirillovich Kryzhnyi. - Kharkov: KhAl. - 1980. - 187 p.

4. Romanovskii, V.P. Spravochnik po kholodnoi shtampovke: spravochnoe izdanie. [Handbook of Cold Stamping] 6-e izd., pererab. i dop. / V.P. Romanovskii. Leningrad: Mashinostroenie. $-1981 .-782$ p.

5. Bychkov, S.A. Kontseptsii primeneniya i realizatsii impul'snykh tekhnologii v usloviyakh opytnogo i seriinogo proizvodstva transportnykh samoletov. [Concepts of application and implementation of impulse technologies in the conditions of pilot and serial production of transport]: dis. d-ra tekhn. nauk. I Sergei Andreevich Bychkov. - Khar'kov: KhAl. - 1991. - 380 p.

6. Valiev, S.A. Kombinirovannaya glubokaya vytyazhka listovykh materialov. [Combined deep drawing of sheet materials] / S.A. Valiev. - Moscow: Mashinostroenie. - 1973. - 176 p.

7. Noritsin, I.A. Teoreticheskii analiz protsessa vytyazhki listovogo materiala. [Theoretical analysis of the drawing process of sheet material] / I.A. Noritsin, // Izv. AN SSSR, OTN. - 1951, - №11. - pp. 1696 - 1703. 
8. Petrakovskii, V.S. Otsenka shtampuemosti materialov pri gidroudarnoi vytyazhke listovogo metalla. Impul'snye metody obrabotki metallov [Assessment of the stampability of materials during hydropercussion drawing of sheet metal. Impulse methods of metal processing] / V.S. Petrakovskii. - Minsk: Nauka i tekhnika. - 1977. - pp. 123 - 131.

9. Yas'ko, S.G. O stepeni vliyaniya konstruktivno-tekhnologicheskikh faktorov na protsess pnevmoudarnoi vityaguvannya [Bout the degree of influence of constructive and technological factors on the process of pneumatic shock whirling] / S.G. Yas'ko // Otkrytye informatsionnye i komp'yuternye integrirovannye tekhnologii: sb. nauch. tr. Khar'kov: Nats. aerokosm. un-t "KhAl", - 2018. - vol. 79. - p. 31-37.

10. Manaenkov, I.V. Reznichenko, N.K., Frolov, E.A. Povyshenie tochnosti i kachestva rabochikh poverkhnostei detalei metodom pnevmoudarnoi shtampovki [Improving the accuracy and quality of the working surfaces of parts by pneumatic impact stamping] / I.V. Manaenkov, N.K. Reznichenko, E.A. Frolov // Mashinostroenie: zb. nauk. pr. Ukr. inzh.-ped. akad. Kharkiv: UIPA. - 2012. № 9. - pp. $142-147$.

Поступила в редакцию 18.12.2019. Рассмотрена на редколлегии 20.12.2019.

\section{Determination of technological factor effect upon intensification of pneumatic impact extrusion and accuracy of extruded parts}

This work is devoted to experimental studies to determine the influence of technological factors on the process of intensification of pneumatic shock punching by drawing and accuracy of stamped products. The process of pneumatic shock extraction, as well as other impulse methods of extraction (explosive, electrohydraulic and magneto-pulse) is complicated by the high speed of deformation and, accordingly, by the occurrence of considerable inertial forces that counteract the movement of the flange of the extracted part. In the case of pneumatic shock reduction of the deformation rate can be achieved by adjusting the relative weight of the striker or by applying a two-stroke stretching. It is experimentally confirmed that the greatest influence on the limit values of the stamping ability in pneumatic impact stamping have the properties of the workpiece material, its surface properties, the scheme of the deformation process, the rate of deformation, the geometry of the matrix or punch, the value of contact friction and intensification techniques. Experiments have shown that the following factors have the greatest influence on the ultimate degree of drawing and the quality of the products: the condition of the surface and the physical and mechanical properties of the workpiece material; the radius of curvature of the working edge of the matrix; the relative thickness of the workpiece; workpiece loading rate (parameter $\alpha$ ); the frictional properties of the matrix material and the workpiece; quality of greasing; technological scheme of operation. For two-stroke stretching, the stretching limit is increased by $8-10 \%$. Also, when using two-stroke load, as shown by experiments, the amount of thinning in dangerous sections of the finished product is reduced. The reduction of radial deformation in the centre of the samples reaches $20-25 \%$. The accuracy of pneumatic shock punching by a liquid is very high, since the deviation of the measured diameters does not exceed $0.1 \mathrm{~mm}$. The surface quality of the pneumatic impacted products is determined only by the surface quality of the starting material. 
The pneumatic shock method of punching using a two-stage folded dash allows to increase the degree of drawing, accuracy and quality by means of a two-stroke loading, that is, to intensify the process of deep drawing of sheet products. The intensification is due to the successive double shock load for one cycle of the PUSH installation - the first blow is a formative, and the subsequent blow of the second stage is a calibration.

Keywords: intensification, pneumatic impact, punching, double impact, compound firing.

\section{Сведения об авторах:}

Фролов Евгений Андреевич - доктор технических наук, профеессор, кафедра технологии машиностроения, Национальный университет «Полтавская политехника имени Юрия Кондратюка», г. Полтава, Украина; e-mail: frolov.poltntu@gmail.com; ORCID:0000-0002-2691-5386.

Драгобецкий Владимир Вячеславович - доктор технических наук, профрессор, Кременчугский национальный университет имени Михаила Остроградского, заведующий кафедрой «Технология машиностроения»; г. Кременчуг, Украина; e-mail: vldrag@kdu.edu.ua. ORCID:0000-0001-9637-3079;

Ясько Станислав Георгиевич - старший преподаватель кафедры технологии машиностроения, Национальный университет «Полтавская политехника имени Юрия Кондратюка», г. Полтава, Украина; e-mail: s.g.yasko@gmail.com; ORCID:0000-0001-6228-705X.

\section{About the Authors:}

Frolov Evgeniy Andreevych, Doctor of Technical Sciences, Professor, National University "Yuri Kondratyuk Poltava Polytechnic», Poltava, Ukraine; e-mail: frolov.poltntu@gmail.com; ORCID:0000-0002-2691-5386.

Volodymyr Dragobetskii, Doctor of Technical Sciences, Professor, Head of the Department of Manufacturing Engineering Kremenchuk Mykhailo Ostrohradskyi National University, Kremenchuk, Ukraine vldrag@kdu.edu.ua. ORCID: 0000-0001-9637-3079.

Yasko Stanislav Georhyevych, postgraduate Poltava National Technical Yuri Kondratyuk University, Poltava, Ukraine; e-mail:s.g.yasko@gmail.com; ORCID:0000-0001-6228-705X. 